\title{
The Effect of Obesity on Musculosceletal System
}

\author{
V. Knap (Viliam Knap)1,2, P. Ondova (Perla Ondova) ${ }^{1}$, M. Istonova \\ (Miriam Istonova) $^{1,2}$, K. Oravcova (Katarina Oravcova) ${ }^{1}$
}

${ }^{1}$ Pavol Jozef Safarik University, Faculty of Medicine, Department of Physiatry,

Original Article Balneology and Medical Rehabilitation, Rastislavova 43, Kosice, SK.

${ }^{2}$ St. Elizabeth University of Health and Social Sciences, Palackeho 1, Bratislava, SK.

\section{E-mail address:}

viliam.knap@upjs.sk

\section{Reprint address:}

Viliam Knap

Department of Physiatry, Faculty of Medicine, Balneology and Medical Rehabilitation

Pavol Jozef Safarik University in Kosice

Tr. SNP 1

04001 Kosice

Slovakia

Source: Clinical Social Work and Health Intervention

Pages: $72-78$

Volume: 12

Issue: 5

\section{Reviewers:}

Roberto Cauda

Institute of Infectious Diseases, Catholic University of the Sacred Heart, Rome, IT

Vitalis Okoth Odero

Catholic university of Eastern Africa, Nairobi, KE

\section{Keywords:}

Obesity. Body Mass Index - BMI. Musculoskeletal System. Prevention.

\section{Publisher:}

International Society of Applied Preventive Medicine i-gap

CSWHI 2021; 12(5): 72 - 78; DOI: 10.22359/cswhi_12_5_11 CC Clinical Social Work and Health Intervention

\section{Abstract:}

Obesity arises and persists during an excessive long-term positive energy balance. Risk factors for the development of obesity are, in particular: a high-calorie diet, low physical activity; adaptation to a sedentary lifestyle; irregular diet. The most commonly used criterion for assessing obesity is the Body Mass Index - BMI. The incidence of obesity in Europe is between $10 \%$ to $25 \%$ in women, while more than $50 \%$ of the population in most European countries is overweight and obese. The effect of obesity on the musculoskeletal system is demonstrable in patients who suffer its consequences during their life. Long-term overweight is the cause of excessive strain on bones, joints and muscles, which over time, due to the chronic course of obesity, affects almost every obese individual. Obe- 
sity prevention programs, the development of a healthy lifestyle, healthy eating and exercise-related activities are our common goals for preventing obesity.

$\mathrm{BMI}=\frac{\text { weight in } \mathrm{kg}}{(\text { height in } \mathrm{m})^{2}} \quad \begin{aligned} & \text { for example height of } 171 \mathrm{~cm}, \quad \mathrm{BMI}=\frac{100}{\text { weight of } 100 \mathrm{~kg}} \\ & 1,71 \mathrm{~m}^{2}\end{aligned}=34$ (severe obesity)

\section{Introduction}

Obesity is defined as a chronic disease characterized by an increase in body fat stores which is no longer just a cosmetic problem, but an over all health problem. People who are overweight have serious health risks: such as diabetes; cardiovascular and respiratory diseases; high blood pressure; joint diseases; cancer. Obese people have not only health problems, but also social and mental problems. They may suffer from: depression; inferiority complex; often have reduced self-esteem; difficulty being successful at work.

\section{Classification of obesity}

We distinguish between primary obesity, the primary cause of which is an imbalance between energy intake and expenditure, caused by excessive food intake. Secondary obesity is usually caused by another disease. Obesity can be:

1. An android type, a so-called male-type or central-type obesity, with a distribution of fat in the torso and abdomen, which is considered more risky. In this type of obesity, visceral fat accumulates in the abdominal cavity. The visceral fat is highly metabolically active and, among other things, produces hormones and cytokines that mediate a further increase in obesity and development of metabolic complications.

2. A gynoid type, a so-called female-type, with fat accumulation in the hip area, which is less dangerous for the patient than the previous type. Abdominal obesity is associated with metabolic and cardiovascular diseases, often combined into a metabolic syndrome. Abdominal obesity is defined by a waist circumference greater than $>88 \mathrm{~cm}$ in non-pregnant women and $>102 \mathrm{~cm}$ in men.

The most commonly used criterion for assessing obesity is the Body Mass Index - BMI. Today, body mass index (BMI expressed in $\mathrm{kg} / \mathrm{m} 2$ ) is the most common measure for the expression of underweight, overweight and obesity in adults. It is calculated as the weight in $\mathrm{kg}$ divided by the square of the height in meters.

\section{Classification of overweight and obesity according to the World Health Organization}

\begin{tabular}{|c|c|c|}
\hline Normal weight & $\begin{array}{c}\mathrm{BMI} \\
18,5-24,9\end{array}$ & zero risk \\
\hline Overweight & $\begin{array}{c}\mathrm{BMI} \\
25,0-29,9\end{array}$ & (low-risk) \\
\hline Class 1 obesity & $\begin{array}{c}\mathrm{BMI} \\
30,0-34,9\end{array}$ & $\begin{array}{c}\text { (moderate- } \\
\text { risk) }\end{array}$ \\
\hline Class 2 obesity & $\begin{array}{c}\mathrm{BMI} \\
35,0-39,9\end{array}$ & $\begin{array}{c}\text { (high-risk) } \\
\text { Class 3 obesity }\end{array}$ \\
$\begin{array}{c}>=40,0 \\
\mathrm{BMI}\end{array}$ & $\begin{array}{c}\text { (life- } \\
\text { threatening } \\
\text { risk) }\end{array}$ \\
\hline
\end{tabular}

(WHO, 2021)

Reducing body weight by $5-10 \%$, an obese patient achieves the greatest health benefit at the beginning of treatment. The results of several world studies confirm that reducing body weight by 5 to $10 \%$ and maintaining it for a long time reduces the risk of premature death as well as the development of several serious diseases.

\section{Pathogenesis of obesity}

Obesity arises and persists during an excessive long-term positive energy balance. Risk factors for the development of obesity are, in particular; a high-calorie diet; low physical activity; adaptation to a sedentary lifestyle; irregular diet. In practice, energy intake is higher than energy expenditure, with excess kilocalories being stored as fat stores. 


\section{Epidemiology of obesity in Slovakia and in the EU}

The incidence of obesity in Europe is between $10 \%$ to $25 \%$ in women, while more than $50 \%$ of the population in most European countries is overweight and obese. Only in the recent 10 years, the number of obese people has increased by 10-40\%. (Pauco, 2021). In 2019, the Public Health Authority of the Slovak Republic carried out a survey entitled "Health Awareness and Behavior of the Residents of the Slovak Republic". It was conducted within Slovakia, the research sample consisted of 3,744 respondents aged 15 and over.

The BMI survey found the occurrence of:

1. overweight (BMI: $25.0-29.9$ ) in $35.6 \%$ of the respondents,

2. class I obesity (BMI: $30.0-34.9$ ) in $12.2 \%$ of the respondents,

3. class II obesity (BMI: $35.0-39.9$ ) in $2.3 \%$ of the respondents,

4. class III obesity (BMI: 40 \& over) in $0.4 \%$ of respondents. (www. uvzsr.sk, 2021).

The onset of childhood obesity in the Slovak Republic began in 2000 with a delay of approximately 15-20 years compared to other industrially and economically developed European countries. According to the COSI Study (Childhood Obesity Surveillance Initiative) organized by the WHO in 2015 , in line with national criteria, $9.9 \%$ of boys aged 8 years were overweight; $8.8 \%$ were obese in Slovakia. The prevalence of overweight in girls of the same age was found in $7.5 \%$; obesity in $9.5 \%$. The share of obese children in Slovakia corresponds to the average of the European countries evaluated within the COSI project. The problem is that approximately $75-80 \%$ of obese children remain obese in adulthood which is of course associated with an increase in diseases accompanying overweight and obesity. Overweight and obesity in children and adolescents are also associated with an increase in type 2 diabetes mellitus. According to statistics from the countries of the Organization for Economic Co-operation and Development (OECD), 1 in 6 children was overweight or obese. Over the course of 5 years, obesity has spread more slowly than before. However, today, new OECD findings confirm an increase in obesity in all surveyed countries, up to tenfold. The world is going through a very rapid nutritional and epidemiological transition. Following a statistical survey of 23 European countries by the European Childhood Obesity Surveillance Initiative (COSI), $14 \%$ of boys; $10 \%$ of girls were obese at the age of 7-8 years. According to the WHO, in the European Union, 1 in 8 children aged 7 to 8 is obese. (see Table No. 1, 2) (Fabryova, 2020; Folentova, 2015; Rybanska, 2019;).

WHO has declared obesity a global epidemic due to its far-reaching health and social conse-

\section{Table 1}

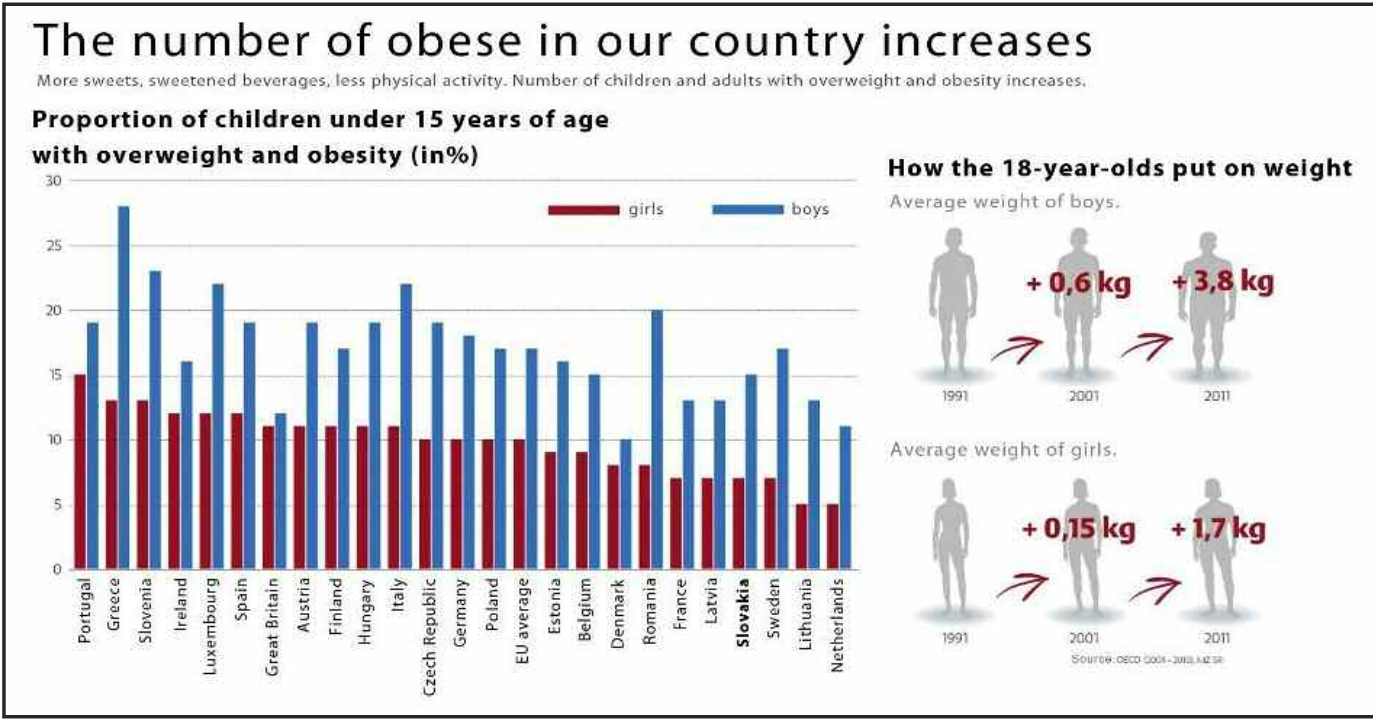

(Folentova 2015) 
quences, and just like the European Union, considers the fight against obesity to be one of its top priorities. Enormous financial resources are spent on the treatment of obesity and the associated health complications in many fields of medicine, but especially in: internal medicine; diabetology; cardiology; gynecology; orthopedics; neurology; and, last but not least, in surgery. Worldwide, statistical assessment of mortality ranks obesity and its complications among the 3 most common causes of death in the population between the age of 50 and 70. In the younger generation (age group 25-35 years), severe forms of obesity increase the risk of premature death by almost tenfold compared to the life prognosis of non-obese people of the same age.

\section{Health risks of obesity and its socio-economic consequences}

Obesity causes a significant increase in morbidity, disability and mortality, worsens the quality of life. The direct healthcare costs of obesity in Europe are estimated at $2-8 \%$ of total healthcare costs, which is comparable to diseases such as cancer.

Obesity is one of the biggest public health challenges of the 21 st century. Over the last two decades, the incidence of obesity has tripled in the EU region, which is a particularly alarming trend. The rising trend of obesity is especially alarming in children and adolescents. The annual rate of increase in the prevalence of childhood obesity is steadily rising. (Rybanska, 2019; Fabryova, 2020)

The current rate is ten times higher than in the 1970s. More than $60 \%$ of children who are overweight before puberty will be overweight even in early adulthood, which is particularly worrying as it can lead to a reduction in the average age at which non-communicable diseases develop. This greatly increases the cost of healthcare services, as such people need healthcare for much of their lives. Unhealthy eating and lack of physical activity contribute to overweight and obesity, which are among the main risk factors for non-communicable diseases. Overweight and obesity are responsible for approximately $80 \%$ of cases of type 2 diabetes in adulthood, $35 \%$ of ischemic heart disease cases and $55 \%$ of cases of hypertension in adulthood. Overweight is also a risk factor for cancer of the colon, breast, endometrium. Obesity also has negative effects on psychosocial health and personal quality of life. Systematic research shows that childhood obesity is closely linked to risk factors for: cardiovascular disease; diabetes;

\section{Table 2}

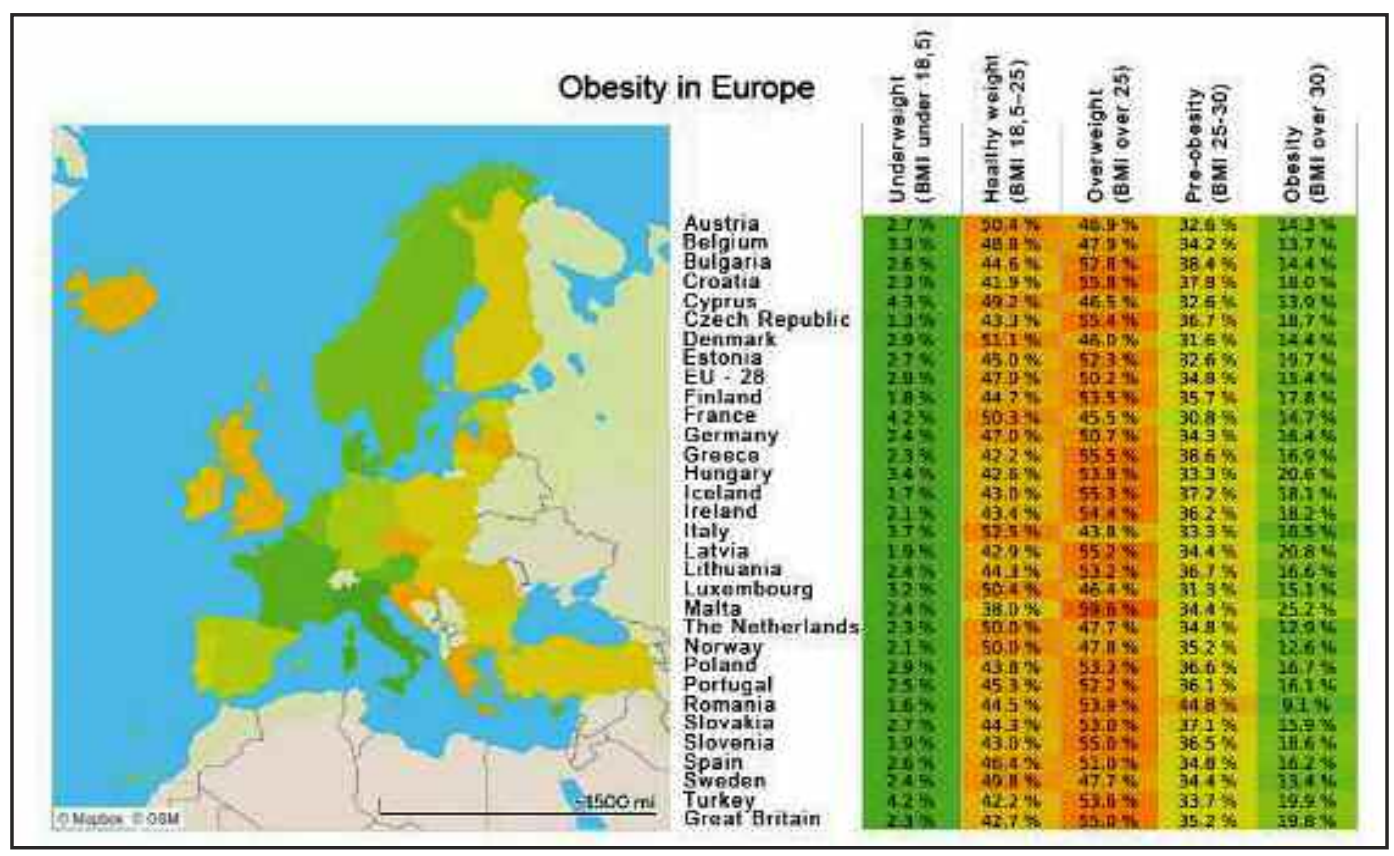

(Eurostat, 2014) 
orthopedic problems; mental disorders. High BMI during adolescence is a prerequisite for high mortality and cardiovascular diseases in adulthood even when a person loses the excess weight. It is alarming that children are now more often victims of many health conditions associated with obesity which were once associated with the adult population. (Rybanska, 2019; Fabryova, 2020)

Effective regulation of obesity requires an integrated approach of several ministries, including comprehensive long-term conceptual measures. Nutritional interventions at school, in the workplace and in communities have shown moderate effectiveness in preventing obesity. Nutritional control can bring several positives, but care must be taken as negative consequences such as loss of non-fat tissue, growth retardation and worsening of eating disorders may also occur. Strategies for food services, health and physical education, games and sports need to be integrated and all professionals should be invited to develop the concepts. Weight control programs combined with increased physical activity, frequent walks, and activity program development can increase the effectiveness of obesity treatment. Even if we do not manage to reduce obesity itself, we can, at least reduce the morbidity. The participation of parents in the treatment program is important for the successful reduction of body weight in young children and partly also in adolescents. (Rybanska, 2019; Fabryova, 2020).

\section{The effect of obesity on the musculoskeletal system}

The weight-bearing joints and especially the articular cartilage are constantly exposed to mechanical stress. This process occurs in both, asthenic and obese individuals. In a case of an obese group of patients with increased body weight, during walking, the mechanical load acting on the cartilage increases to 2 to 3 times the weight. Mechanoreceptors which are activated when the joint is overloaded react on the surface of chondrocytes. Overloading causes complex biochemical processes leading to its destructive processes. Activation of mechanoreceptors thus damages articular cartilage and causes osteoarthritis (Gerykova, 2013).

\section{Low back pain}

As a result of obesity, the ratio between adipose and muscle tissue changes in favor of the adipose tissue. As a result, the abdominal, sciatic and other muscles are weakened. A weakened abdominal wall causes a change in the position of the pelvis towards the front, which we call the anterior position of the pelvis. This process causes an increase in lumbar lordosis. The result of this process is an overload of the lower thoracic, lumbar and sacral spine. The load on the ligaments, plates, joints, back muscles increases, and they respond with painful signaling to the central nervous system. These pains, which occur in the lower back, are referred to as "low back pain" (Bener, et al., 2003).

\section{Lower cross syndrome}

In patients with low back pain, during a complex physiotherapeutic examination, we often find a lower cross syndrome, with a manifestation of shortening of the hip flexors. On the one hand we find weakened abdominal muscles, on the other hand, there are weakened hip extensors. There is also an overload of paravertebral muscles with the occurrence of painful myofascial trigger points. As a result of the muscle dysbalance, incorrect posture occurs (Kolar, 2009).

\section{Muscle dysbalance}

The onset of muscle dysbalance is manifested by a weakened abdominal wall which causes

development of lumbar hyperlordosis; there is an increased load on the intervertebral discs which can lead to degenerative and destructive changes. We call this process spondylosis as a manifestation of a degenerative condition of the intervertebral spaces. Due to the damage of the discs, the spinal ligaments elongate and lose their stabilizing function, and subsequently the instability of individual sections of the spine arises. The ligaments lose their function and therefore the back muscles start to replace their function, especially the paravertebral ones. After a certain time, these muscles and muscle groups are also overloaded and painful reflex changes occur. Body's response to this change is the formation of bone spurs, the so-called osteophytes which on one hand reduce the pain caused by reflex spasms, but on the other hand also limit the mobility of the spine. The process of spondylosis continues with the transition to spondylarthrosis (Gerykova, 2013). 


\section{Spondylarthrosis}

Spondylarthrosis is an osteoarthritis of the intervertebral joints with similar symptoms. Its formation is preceded by the narrowing of the intervertebral disc. Osteophytes growing on the edges of vertebrae can suppress the spinal cord or spinal roots as they grow. This process can also occur with intervertebral disc prolapse due to its uneven load in hyperlordosis. (Gallo et al., 2011).

\section{Enthesopathy}

The most common tendon disorders caused by obesity are enthesopathy of the short muscles of the sole of the foot. We are talking about: tendon pain of musculus flexor digitorum brevis;

musculus quadratus plantae; musculus abductor pollicis longus. This disease is manifested by; pain in the heel bone, initially it occurs after periods of inactivity; later pain also occurs during or after the physical activity. We can also bring the pain by palpation; we can observe swelling in the given locality and crepitus in the place of muscle insertion above the heel. The muscles are in hypertension and often palpably painful. The biomechanics of the foot are broken. During long-term difficulties, a heel spur (calcar calcanei) forms on the heel bone, which then suppresses the surrounding soft structures, such as the subcutaneous tissue and skin. When walking, when they are suppressed by the weight of the body, the patient feels pain with increasing intensity. Another disease of overloading is plantar fasciitis, which manifests itself with the same symptoms. Unlike enthesopathy, it affects the short muscles of the sole of the foot, the attachment of the plantar fascia, down to th'e projection of the heel bone (Dobea et al., 2009; Gallo et al., 2011; Gerykova, 2013).

\section{Prevention and treatment}

Obesity prevention programs, the development of a healthy lifestyle, healthy eating and exercise-related activities are our common goals for preventing obesity. In today's modern times, there are several forms of pharmacological treatment that are selected on the basis of BMI values and potential comorbidities, such as hyperlipidemia, high blood pressure or worsened glucose tolerance. The main goal of the treatment is change in weight; another goal is to reduce the complications associated with obesity. We must not forget preventive measures in the field of health policy where it is necessary to focus on high-risk young people and the child population in connection with families and schools. Properly set up processes for the prevention and treatment of obesity lead to a healthy diet and make an effort to improve the environment, by which they help to develop sports activities. (Rybanska 2019).

At the same time, regular exercise serves as an effective prevention of weight gain and of development of the mentioned cardiovascular and metabolic diseases associated with obesity or overweight. Regular healthy movement brings beneficial effects to: the human body; the cardiovascular; respiratory; metabolic and locomotor system. Physical activity in obese patients has a beneficial effect on blood sugar levels, which significantly reduces the risk of developing or worsening of the type 2 diabetes mellitus. By increasing metabolism, it also helps to regulate cholesterol levels; more specifically it regulates the ratio between HDL and LDL, thus preventing the development of atherosclerosis and possible clinical complications resulting from it. The loss of fat stores reduces peripheral resistance, which results in an adjustment of blood pressure in hypertensive patients and we achieve regularity of heart rate. In skeletal muscle, metabolic reconstruction of muscle fibers occurs on the basis of demands placed on the muscle and its activity. (Rybanska, 2019; Fabryova, 2020).

\section{Conclusion}

The effect of obesity on the musculoskeletal system is demonstrable in patients who suffer its consequences during their life. Long-term overweight is the cause of excessive strain on bones, joints and muscles, which over time, due to the chronic course of obesity, affects almost every obese individual. Obesity is also a factor that causes various difficulties and complications in the treatment of the diseases of the musculoskeletal system. We can slow down overweight and obesity if our society focuses on the causes of their origin. Prevention, which should be linked to the school environment in relation to a combination of healthy diet and physical activity, is essential. In addition to the school environment, the home environment is also very important because with parents promoting a healthy lifestyle, enough ex- 
ercise and a healthy diet, we can stop obesity. It is the habits that children acquire at home, associated with healthy eating, exercise and the right choice of food, that can transfer to other aspects of life and thus they will decide to be sufficiently physically active. Promoting various physical activities csn help reduce the incidence of risk factors for non-communicable chronic diseases. Maintaining adequate physical activity throughout life of the population is a key task of the EU's national population health programs as this is the way we can prevent obesity in practice.

\section{References}

1. BENER A et al. (2003) Obesity and low back pain. Collegium antropologicum [online]. 2003, vol. 27, no. 1, pp. 95-104, [cit. 20218-13]. ISSN: 0350-6134. Available online: www: http://hrcak.srce.hr/ index.php?show= clanak\&id_clanak_jezik=44182.

2. CERVENY R (2009) Obesity. Postgraduate medicine. Professional magazine for doctors. Prague: Mlada fronta a.s. 2005, vol. 11, no. 7, p. 766-773. ISSN: 1212-4184.

3. DOBES M et al. (2009) Ankle and foot. In Kolár P. et al. Rehabilitation in clinical practice. Praha: Galén, 2009. ISBN 978-80-7262-657-1.

4. FABRYOVA L (2020) Creation of new and innovative procedures for prevention and their introduction into medical practice, No 3, Vol. 2020, ISSN 2644-6251 (online), ISSN 2644-5824.

5. FOLENTOVA V (2015) The number of obese children and adults is increasing. Bratislava. DN. N press. ISSN 1339-844X.

6. GERYKOVA E (2013) Obesity and its effect on the musculoskeletal system. [online],2013 [cit. 2021-8-13]. https://theses.cz/id/lb44zr/ 00182227-391392154.pdf.

7. RYBANSKA D, VYSKOC A (2019) Obesity - a health problem of the child generation. Public health. [online]. 2019, vol. 15, no. 1, p. 1 -60. Available online: ISSN 1337-1789.

8. OECD (2018) Health at a Glance:Europe 2018 [online], 2019.[cit. 2019.04.12]. Dostupné na: https://www.oecd.org/health/health-at-a-glance-europe-23056088.htm.

9. EUFIC (2019) Childhood Obesity Review [online],2019. [cit. 2019.04.22]. Available online: https://www.eufic.org/en/healthy-living/article/childhood-obesity-review. 